\title{
The Use of the Clinical Immunology Laboratory
}

\section{Steven H. Yoshida,' Bruce C. Veit, ${ }^{2}$ Lyndon E. Mansfield, ${ }^{3}$ and M. Eric Gershwin ${ }^{\star 1}$}

\author{
'Division of Rheumatology, Allergy and Clinical Immunology, \\ University of California at Davis, Davis CA 95616; '2Department \\ of Clinical Investigations, William Beaumont Army Medical Center, \\ El Paso, TX; ${ }^{3}$ nternal Medicine, Texas Tech University \\ and University of Texas, EI Paso, TX
}

\section{Introduction}

The clinical immunology laboratory uses a variety of instruments and technologies to provide researchers and clinicians means to study the immune system and its components. It also functions to perform various diagnostic tests of both humoral and cellular immune activities. Standard immunochemical methodologies include immunoelectrophoresis and various assays based on gel precipitation of proteins. The analysis can be qualitative or quantitative measures of antibody and complement activity. Other matrices, such as latex or red cells, will agglutinate to reveal antigen or antibody presence and relative amount. Serological techniques can also use the properties of immunofluorescence, and complement fixation. Classical analytical methods for the study of cellular immune function include T- and B-cell responses to mitogens or antigens, and B-cell immunoglobulin synthesis in vitro. The increased DNA synthesis, observed when leukocytes from two different individuals are cocultured (mixed leukocyte reaction), is used to measure the degree of histocompatibility.

One must emphasize, however, that the use of immunologic testing is not a substitute for a careful history and physical examination. Too often, a patient is subjected to an extensive array of tests, many of which are not standardized and have considerable

*Author to whom all correspondence and reprint requests should be addressed. 
Table 1

Cellular Parameters Measured by Flow Cytometry

\begin{tabular}{ll}
\hline \multicolumn{1}{c}{ Structural } & \multicolumn{1}{c}{ Functional } \\
\hline Cell size (1,2) & Membrane integrity (23-25) \\
Cell shape $(3,4)$ & Membrane permeability $(26,27)$ \\
Cytoplasmic granularity (5-7) & Enzyme activity $(28,29)$ \\
Pigment content (e.g., hemoglobin, & Endocytosis $(30,31)$ \\
$\quad$ lipofuschins) $(8,9)$ & Intracellular pH $(32,33)$ \\
Protein fluorescence & \\
$\quad$ (e.g., tryptophan) $(10,11)$ & Intracellular receptors $(34,35)$ \\
DNA content $(12-14)$ & DNA synthesis $(36,37)$ \\
DNA base ratio $(15,16)$ & Membrane fluidity $(38,39)$ \\
Chromatin structure $(17,18)$ & Surface receptors $(40-45)$ \\
RNA content $(19,20)$ & Cytoplasmic/mitochondrial \\
Total proteins $(21,22)$ & membrane potential $(46,47)$ \\
Basic proteins $(21,22)$ & Cytoplasmic Ca ${ }^{2+}(48-50)$ \\
\hline
\end{tabular}

interindividual and even intraindividual variation. Such testing is expensive and often has no clinical utility. It may even obscure a diagnosis or confuse the clinician. With this in mind, we have chosen to focus in detail on four newer technologies that are of particular interest and usefulness to the contemporary clinical immunologist. These are flow cytometry, monoclonal antibody technology, the enzyme-linked immunosorbent assay, and recombinant DNA technology. We first present the basic concepts by which these methods operate. These are followed by the application of these methods to the study of the gp120 envelope protein of the human immunodeficiency virus (HIV).

\section{Methods and Techniques}

\section{Flow Cytometry}

Basically, the process employed by flow cytometry is the separation of individual cells or other units of biological materials in a stream of liquid. These units are forced to flow in single file past sensors that measure physical or chemical characteristics. Flow cytometry can analyze materials as varied as immune complexes, liposomes, cellular organelles, chromosomes, individual virus particles, bacteria, fungi, eukaryotic cells, cell hybrids, cell aggregates, and even small multicellular organisms, such as brine shrimp. Table 1 shows a list of various applications of flow cytometry in analyzing cell structure and function, with representative references in parentheses. 
Typically, whole or separated blood components, or a piece of tissue from an organ or tumor biopsy, are prepared as a single cell suspension. The cell suspension is placed in a pressurized chamber and driven in a laminar and concentrically flowing sheath (usually composed of saline) through the flow cell. This process, called hydrodynamic focusing, produces a laminar flow without mixing sample and sheath. Hydrodynamic focusing forces cells to flow in a narrow stream through the laser beam that transects the stream horizontally. The driving pressures for the sheath and sample are individually regulated. The velocity at which a cell passes through the laser beam is determined by the sheath flow pressure. The sample pressure influences the sample flow rate and the sample stream core diameter. A low sample drive pressure reduces sample delivery rate and stream diameter. For example, the cells will be confined more strictly to a single path through the laser beam. The sheath fluid drive pressure regulates the velocity of the sheath flow, which causes expansion or reduction of the sample core.

Depending on its design, the cytometer can use up to three laser sources simultaneously. The multiple light sources are aligned along a single excitation axis, in which they intersect the flow of cells at a perpendicular angle. Cells pass through the light beams in single file and interfere with the light path, resulting in light scattering in all directions. Axial light loss, or the drop in energy, is detected by a photodiode, which produces a signal proportional to the loss of light energy. Forward light scatter is detected by fiber optics, which direct the light to a photomultiplier tube. The tube amplifies the signal for conversion into electrical energy. The two signals are then processed to give information on cell size, refractive index, and granularity. In this way, it is possible to identify cell subpopulations without using specific chemical markers. For example, based on light-scatter information, peripheral blood lymphocytes, monocytes, and granulocytes can be distinguished.

Additional information may be gained through the analysis of specific cellular components. In this case, the cells are placed in a solution containing a fluorescent dye or a specific fluorescent antibody to a cell marker. Fluorescent emissions resulting from laser excitation of bound fluorochromes are detected by long- and shortwavelength fiber optics. These transmit signals to photomultiplier tubes in direct proportion to the amount of fluorescent signal detected.

The analog signal pulses are routed to circuits that respond only to signals above a set threshold or within selected amplitude limits. The signals are selected individually or in temporal pairs. They are 
displayed and/or recorded in different singular or combined forms on an oscilloscope. Signal analysis is visually expressed as "channels." Channels can be thought of as the $x$ axis of a bar graph (histogram) or the $x y$ coordinates of a scatter plot (cytogram). A histogram is used to represent a frequency distribution of a single input signal, such as size. The cytogram provides a two-parameter array, for example, size and granularity. Thus, two independent characteristics of an individual cell can be simultaneously evaluated and represented by a cytogram. Information on the frequency of size distribution, internal structure, or fluorescence of a cell is stored in each channel that appears on the histogram or cytogram. Definable regions within a histogram or cytogram make possible counts of the entire cell population or subpopulations.

The most complex use of flow cytometry is the concurrent identification, characterization, and physical isolation of individual subpopulations of cells from larger, mixed populations. For example, one may need to know if the distribution of DNA in a lymphocyte subpopulation is associated with a specific cell-surface antigen. This can be done by staining cells with fluorochromelabeled antibodies specific for the antigen of interest followed by sorting. Flow sorting employs electrical and/or mechanical means to select for cells with the desired characteristics. The analytic optical signals are processed to produce electrical pulses that charge the liquid stream. A positive or negative droplet containing the desired cell is formed. Droplets broken off while the stream is charged retain the charge. Downstream, the droplets pass through an electrical field between two charged plates. Charged droplets are deflected into a container or onto a slide while uncharged droplets continue on the original course into a waste container or a third container. The charging plates last for one or more droplet periods, based on the time a cell is expected to enter a droplet. Charging plates are synchronized. All drops formed are charged precisely to ensure an equal charge on each droplet. In this way, the isolation of relatively pure populations of viable cells can be achieved. The sorted cells can then be stained with a DNA fluorochrome and reanalyzed for DNA distribution. With multilaser systems, this information is obtained simultaneously by staining the entire cell population with fluorescent antibodies and DNA fluorochrome. Concurrent measurements of antibody and DNA fluorescence in each cell can then be made. By selecting certain threshold values, the operator can choose all cells whose immunofluorescent signal intensities are above a preselected level used for sorting and DNA fluorochrome analysis. 
Although the most frequent clinical uses of flow cytometry are counting and characterizing cells from peripheral blood samples $(51,52)$, single cell suspensions for flow cytometry analysis are also prepared from solid tissues or tumors, and from adherent cultured cells. Flow cytometry can also monitor bulk methods for the purification of cell populations, such as sedimentation and centrifugation, or affinity column-based separatory techniques. If large cell yields are more important than high purity, bulk separation with flow cytometric monitoring is more efficient than primary sorting. On the other hand, if high purity is required, flow cytometry is more efficient than microscopic analysis when sorting viable cells for further analysis or manipulation, such as cell culture.

Two related problems are associated with the preparation of cells for analysis. The greatest problem with flow cytometry is the need for a test sample to be as monodispersed a suspension as possible. However, procedures that separate cells also remove most adhesion molecules. Adhesion molecules are likely to be important in the cells' behavior. In this sense, the inappropriate use of flow cytometry and single cell suspensions will result in "discarding the baby with the bath water." At that point, it will be preferable to use image analyzers and microspectrophotometers with newly developed image intensifiers and laser scanners. The advantages of these latter instruments are seen in the preservation of the physical organization of the cells being studied

\section{Monoclonal Antibodies}

In 1975, Kohler and Milstein reported their work on producing mouse monoclonal antibodies (MAbs) to sheep erythrocytes (53). Their contribution launched a new era in immunology. Using somatic cell hybridization, it is possible to generate continuously growing hybridoma cell lines, which synthesize and secrete MAbs indefinitely. Since the first report, the use of MAbs has impacted on almost every facet of biology.

MAbs are used in the research laboratory, where they remove a previously worrisome source of variability in antisera. They are the basis for the rapid expansion in clinical diagnostic tests utilizing antibody specificity as their indicator. They also brought simpler and more sensitive assays to the laboratory where cumbersome chemical separations and analyses have been replaced. The entire gamut of measurements that are germane to clinical medicine have been affected. Besides providing the methodology for producing seemingly inexhaustible amounts of homogeneous antibodies with a single specificity, Kohler and Milstein provided a prototype for the development 
of hybrid cell clones that immortalize cells that produce specialized mediators, such as cellular growth factors or other lymphokines. Recently, this same technology has been used for gene mapping and for studies of gene expression and differentiation.

Producing MAbs involves somatic cell hybridization via the fusion of an antibody-producing B-cell and a myeloma cell. The latter is adapted to permanent in vitro growth, but lacks certain metabolic processes, resulting in a requirement for exogenous metabolites. The two cells are brought into close contact and treated with such agents as polyethylene glycol to fuse their plasma membranes. The resulting fusion product contains both nuclei; a cell with two or more dissimilar nuclei is a heterokaryon. In time, the nuclei fuse into a single nucleus with genetic information from both original cells; this is the hybrid. Hybrids usually lose some chromosomes, but retain some properties of each parental cell. The end result is an immortalized antibody-secreting cell.

When producing murine MAbs, the most commonly used myeloma mutants lack the enzymes hypoxanthine-guanine ribosyl transferase and thymidine kinase. These are enzymes used in the salvage pathway for DNA synthesis. Because these cell mutants are unable to utilize hypoxanthine or thymidine, they die when the endogenous synthesis of DNA precursors is blocked with aminopterin. Thus, these cells are unable to use either the salvage or de novo pathways for the synthesis of DNA precursors. On the other hand, the antibody-producing B-cells have an intact salvage pathway (in the presence of aminopterin, their endogenous pathway is also blocked). The cell hybrids, or hybridomas, that are produced from the fusion event can survive in HAT (hypoxanthine, aminopterin, thymidine) medium. This is illustrated in Fig. 1.

The preparation of antibody-producing B-cells for fusion usually involves immunization. Administering an immunogen to animals normally results in the stimulation of a highly heterogeneous population of cells. The degree of heterogeneity will be influenced partly by the purity of the immunogen, as unwanted materials could lead to unwanted antigen specificities. Also, different B-cells with specificities for different sites or epitopes on the antigens will be stimulated. Thus, the structural complexity of the purified antigen is also a factor. Generally, the polyclonality of the immune response is not a problem as long as the desired antibody responses are induced to the degree that the subsequent screening procedures can isolate the hybridomas of interest.

The choice of fusion partners for the B-cells also needs to be considered. This is an especially critical factor in the production of 


\section{NIIIIIIII)}

1 HAT dependent Myeloma

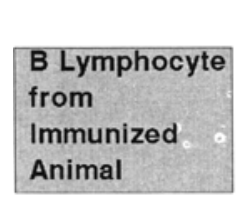

2

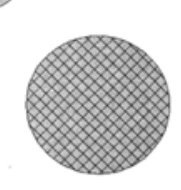

PEG added Cellular Membranes fuse
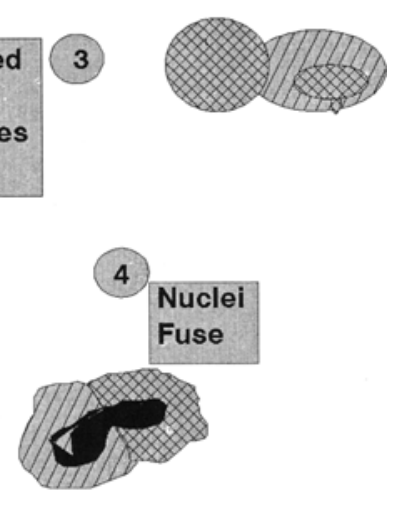

Fig. 1. Hybridoma formation and Mab synthesis and selection.

human MAbs. Although the majority of MAbs have been derived from mice and rats, human hybridomas, which produce human MAbs, are particularly valuable to clinical medicine. For example, if MAbs are to be administered to patients, the problems associated with the rejection of xenogenic proteins are reduced. The production of human MAbs has been impeded by the scarcity of human cell lines that when fused will support the secretion of antibodies (54). HATsensitive murine plasmacytomas have been used with human B-cells to produce mouse $\times$ human hybrids (55-57). However, these interspecies hybrids segregate human chromosomes and render the cell unstable. Hybrids formed from human $x$ human fusions are more stable. Unfortunately, cells of the most differentiated human lymphoid neoplasias, the plasmacytomas, can rarely be maintained in continuous culture. Of those plasmacytomas that have been established in culture, few have the required deficiencies in their salvage pathway enzymes, thus making them not usable as fusion partners.

Difficulties in obtaining suitable human myelomas for producing human $\times$ human hybridomas has prompted investigators to search for lymphoblastoid cell lines among either malignant or normal hematopoietic tissues $(58,59)$. However, lymphoblastoid cell lines initially considered suitable as fusion partners were found to 
be infected with Epstein-Barr virus (EBV), were of polyclonal derivation, and were diploid. The usual result was a relatively low efficiency of fusion. An alternative approach to immortalizing human B-cells has been the use of EBV to directly transform normal B-cells into lines that can then be maintained in long-term continuous culture (60-62). The in vitro infection of human blood lymphocytes with EBV induces polyclonal immunoglobulin secretion. Therefore, it is essential to first purify as much as possible the B-cells that secrete antibodies of a particular specificity prior to transformation. At present, this method has been of limited success because of the low levels of MAbs secreted and problems with the stability of cells in long-term culture.

A critical factor in the successful identification of useful MAbs is the design of a highly selective screening protocol. The screening of clones involves measuring the antigenic specificity of the antibodies produced by them. For example, antibodies to interferon may be detected by their ability to inhibit interferon activity. If MAb recognition of certain cell types or cellular components is needed, those cells or cell materials can be used as reagents to identify the hybridomas secreting such antibodies. In addition to antigenic specificity, other antibody qualities may be chosen. These include avidity, affinity, and other thermodynamic or kinetic parameters. Antibody isotype and biologic activities, such as complement fixation, mitogenesis, agglutination, and opsonophagocytic potential, may also be considered.

MAbs are widely employed, usually after some chemical modification. The most common change is the addition of enzyme, fluorescent, or radioactive tags. The resulting labeled antibodies have been useful in many types of immunologically based assays. For example, radiolabeled MAbs are used as probes in diagnostic imaging for the detection of such malignancies as human colorectal carcinomas (63). Toxic substances, such as ricin, may be covalently coupled to MAbs specific for tumor antigens, which then deliver a toxic drug to the tumor cells. In this way, higher concentrations of antitumor activity can be directed to specific cells (64). Similarly, the conjugation of other chemotherapeutic agents, such as daunomycin to MAbs has been useful in the treatment of certain malignancies (65). MAbs have also found uses in the separation of cells and other materials from mixtures. For instance, reductions in graft-vs-host disease has been achieved by the use of MAbs to remove cytotoxic T-cells in donor bone marrow prior to transplantation (66). Polystyrene-coated magnetic beads have been conjugated to monoclonal antineuroblastoma antibodies. The neuroblastoma cells bound to these conjugates can 
then be removed with a magnetic field (67). Finally, separation columns using MAbs as affinity immunosorbents has eased the purification of natural products or products manufactured by genetically engineered bacteria.

The MAbs themselves can be structurally modified through somatic cell genetics and recombinant DNA technology. The primary nucleotide sequence of the immunoglobulin molecule can be altered by isolating the corresponding genes or DNA fragments and modifying the sequences coding for the heavy $(\mathrm{H})$ and light $(\mathrm{L})$ chains. A variable (V) region of a mouse antibody can be linked to a human constant (C) region, thus making the molecule look more like a human immunoglobulin while retaining the ligand-binding properties of the original mouse antibody.

With the rapid development and refinement of recombinant DNA methodologies, it was certain that MAb production would move from mammalian cell fusion to genetically engineered antibodies produced by prokaryotic cells. The major advantage is speed. Several months are usually required for conventional fusion, cell culture, and screening processes. Genetically engineered antibodies can be produced in 1-2 wk. Recently, Huse et al. (68) reported on a lambda bacteriophage vector system that was used for the insertion of anti-KLH $p$-nitrophenyl phosphonamidate $\mathrm{H}$ - and L-chain gene sequences derived from mouse spleen cells into $E$. coli. The product synthesized by the bacteria was an Fab fragment having specificity for the immunizing antigen. Clinical applications with Fab fragments of antibody molecules are many, including diagnostics and drug-targeting immunoconjugates. The lack of the Fc portion may be advantageous in certain situations, as this decreases clearance, adherence to cells, and complement activation. In other applications, intact immunoglobulin molecules are required. In these cases, the technologies needed to extend the $\mathrm{H}$-chain genes and glycosylate antibodies within mammalian cells are available.

\section{Enzyme-Linked Immunosorbent Assay}

Enzyme-linked immunosorbent assays (ELISAs) were developed as alternatives to radioimmunoassays (RIAs). The initial motivation may have been the relatively onerous precautions required with radioactivity of any sort, and the short half-life of most labels. The precautions necessary for the minimal use of radioactivity added substantially to time and costs of the assays. The first RIAs involved reactant measurements by competitive binding of radiolabeled vs unlabeled antigen with antibody. A separation step was needed to distinguish between bound and unbound labeled antigen. Such 


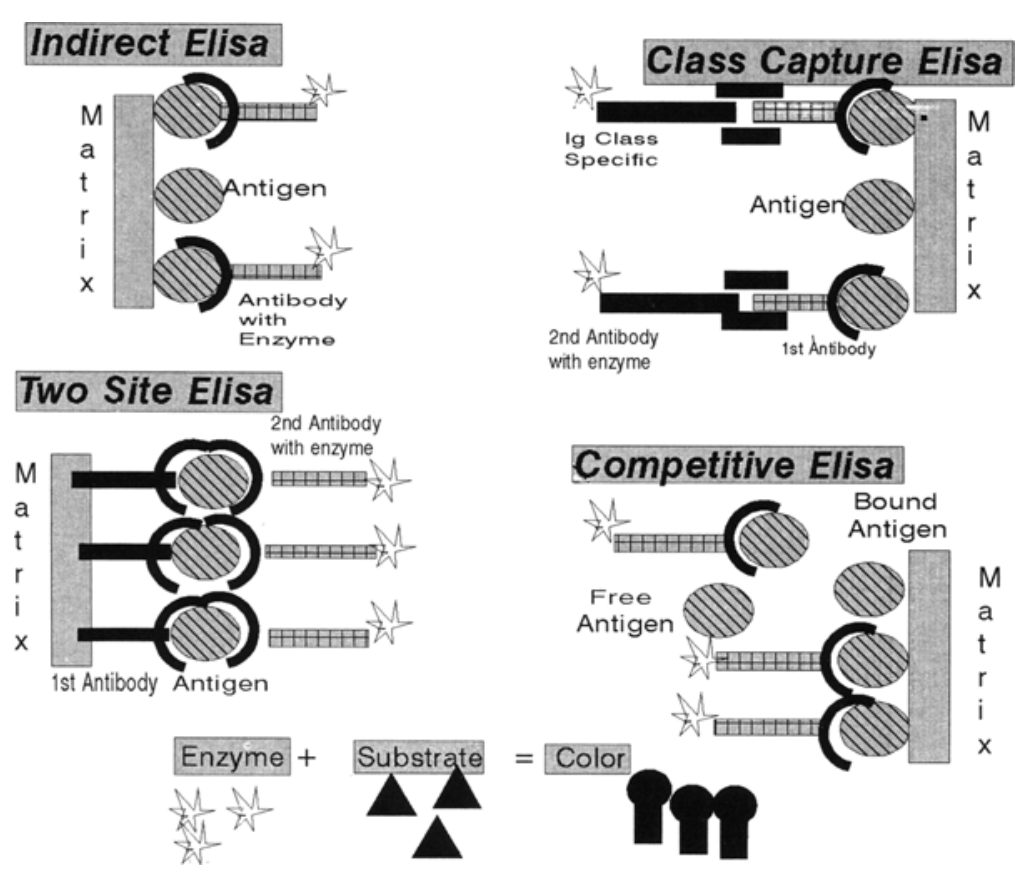

Fig. 2. Different ELISA assays.

agents as ammonium sulfate, polyethylene glycol, trichloroacetic acid, or second antibodies enhanced the precipitation of the antigen-antibody complexes. Later, the precision and speed of separating complexes improved when the second antibody was immobilized onto a "solid phase," such as agarose, plastic, or Staphylococcus aureus Cowan I strain bacteria. This "sandwich" type of RIA used labeled antibodies, rather than labeled antigens. They offered several advantages over the earlier competition type assays.

ELISAs have several advantages over the RIA. The use of radioactive materials has been eliminated. The labeled reagents are stable and can be stored for long periods without loss of activity. Multiwell microtiter plates, which replaced test tubes, are easy to handle and, when used with automated well washers and plate readers, large numbers of plates can be processed in a short period. The use of plate readers, essentially specialized spectrophotometers, has increased the sensitivity of ELISAs to the level of RIAs. Many different types of ELISAs are used in the laboratory (Fig. 2), and a brief description of each of the most commonly used assays follows.

Perhaps the simplest type of ELISA is the indirect or sandwich assay. Antigens, such as the measles virus, are passively bound to a plastic microtiter plate through the use of a "coating buffer." Crude antigen preparations can be sufficient if appropriate controls are 
Table 2

Chromogenic Enzymes and Substrates Used in ELISA

\begin{tabular}{lc}
\hline \multicolumn{1}{c}{ Enzyme } & Substrate \\
\hline Alkaline phosphatase & $p$-Nitrophenyl phosphate \\
Horseradish peroxidase & Orthophenylene diamine 2,2-azino- \\
& diethyl-benzothiazoline-6- \\
& sulfonate 5-amino-salicyclic acid \\
& $3,3,5,5$-tetramethylbenzidine HCl \\
$\beta$-Galactosidase & $p$-Nitrophenyl- $\beta$-D-galactosidase \\
& 4-methylumbelliferyl- $\beta$-D-galac- \\
& tosidase \\
\hline
\end{tabular}

included to distinguish specific, nonspecific, and crossreacting interactions. This step is followed by the addition of antisera, which contain antigen-specific antibodies. These antibodies then bind to the viral antigens. The nonbound material is washed away and the remaining antimeasles antibodies are detected by adding an antihuman immunoglobulin antibody conjugated to a chromogenic enzyme. A large variety of enzyme-conjugated antibodies, including MAbs, are commercially available. They are conjugated with different enzymes, but alkaline phosphatase, horseradish peroxidase, and $\beta$-galactosidase are most commonly used. If the enzyme-labeled antibody is specific for a particular class of immunoglobulin, such as IgM, then class-specific antibodies will be detected. The final step in the ELISA is to remove the nonbound enzyme conjugate and add the appropriate substrate (Table 2). Over time, the enzyme-substrate mix generates detectable color changes, which are measured spectrophotometrically. The enzymatic activity can be stopped with sodium hydroxide, sulfuric acid, or detergent. Otherwise, absorbance levels must be determined at prespecified times.

Concentrations of antigens can be determined using a two-site ELISA. In this assay, antibodies bound to the wells of a plastic microtiter plate are used to capture the corresponding antigen in the test sample. MAbs and polyclonal antibodies have been used. Most polyclonal antibodies bind well to plastic microtiter plates, though certain MAbs do not. In such cases, binding has been increased either by increasing the $\mathrm{pH}$ of the coating buffer or by covalently binding the MAbs to bovine serum albumin. For capture antibodies, the most important requirement, once they are bound to a solid phase, is a high and specific binding capacity for antigen. In those cases where crossreactivity exists, it can be removed by preabsorption with immunoabsorbents. MAbs offer a major advantage in specificity and availability. However, in some cases they may be too 
specific and will not recognize all of the epitopes or antigens that one would like to detect. In these cases, mixtures of MAbs have been used to ensure the presence of all necessary specificities. The antigens thus captured are then detected by a second enzyme-labeled antibody. It is preferable that the two antibodies used are derived from the same species to avoid species crossreactivity. This assay provides a rapid and simple method for antigen detection, particularly when sample and conjugate can be added simultaneously.

The class-capture ELISA is suited to cases in which it is desirable to separate a particular class of immunoglobulins from a sample prior to measurement of antibody activity. The capture antibody must be specific for a single immunoglobulin isotype, such as IgM, in order to detect class-specific antibodies. Otherwise, antigen-specific antibodies of other classes could interfere with these measurements. The primary purpose of this initial step is to eliminate a larger concentration of irrelevant isotypes that might interfere with the detection of the class of interest. Class-capture assays have been used for the detection of specific IgM antiviral antibodies and IgG or IgE antibodies to various allergens. Class-capture assays have many advantages over conventional indirect ELISAs using class-specific enzyme-conjugated antibodies. They avoid competitive inhibition caused by antibodies of the same specificity that may be present in much higher serum concentrations. For example, IgG antiallergen antibodies may be in much greater concentration than $\operatorname{IgE}$ antibodies with the same specificity, making the latter difficult to detect.

In competitive ELISAs, competition for binding to antigen can be done by using an antigen-coated microtiter plate where a fixed level of enzyme-labeled antibody competes with varying levels of unlabeled antibody in the sample. The relative concentrations, epitope specificities, and affinities of the test and competing antibodies are crucial to achieve a sensitive, specific, and reliable assay. Sensitivity can be increased if the unlabeled test antibody is allowed to bind to the antigen before the labeled reagent is added. The signal in all competitive assays is inversely related to the concentration in the sample.

A similar approach can be used to measure antigen in a test sample. In this case, antibody binding to antigen on a solid phase is inhibited by soluble, nonlabeled antigen. The resultant activity is measured by adding an enzyme-labeled antiimmunoglobulin. Such assays have been used to measure the potency of allergen extracts. The presence of soluble antigen in the sample can also be determined by competition with soluble-labeled antigen for binding to antibody on a solid phase. The sensitivity and specificity of the 
procedure is greatly dependent on having a supply of antigen sufficiently pure to allow efficient labeling. The sample must also be appropriately robust to ensure retention of antigenicity during labeling and must possess the same epitope specificity as the test antigen. This method, as with other antigen-detection methods discussed, is affected by the presence of antibody in the sample.

The ELISA can be amplified and sensitivity increased by simple devices. The simplest is by the use of the observed strong binding of biotin to avidin. Generally, antibody conjugation with enzyme is a one-for-one or one-for-two situation. Biotin is a smaller molecule, and 10 or more may conjugate to an antibody without destroying its activity. Avidin has strong-affinity biotin receptors. Such enzymes as alkaline phosphatase can be conjugated to avidin. In this type of ELISA, there is an additional step of binding of avidin-alkaline phosphatase conjugates to biotinylated antibodies. In this way, five or more enzymes will be bound to one antigen-antibody complex. The degree of color developed from any initial antigen concentration will be correspondingly greater, and lower antigen concentrations detectable.

A similar amplification occurs if a second antibody technique is used. The antigen-detecting antibody is unlabeled. The immune complex is disclosed when an enzyme-conjugated antibody recognizing the first antibody is used. Many second antibodies may bind to the first antibody, at differing epitopes. The enzyme activity of the immune complex is proportionally enhanced. The level of detectable antigen is lower than in the direct assay (69).

\section{Genetic Engineering with Recombinant DNA}

Recombinant DNA, as the term implies, is the introduction of a gene or set of genes from a donor source into the recipient strand of DNA. Paul Berg and his coworkers constructed the first recombinant DNA molecule in 1971. They successfully opened the SV40 DNA molecule and spliced it to a bacterial chromosome. This accomplishment introduced a new era in molecular genetics (Fig. 3). The product results in the tandem expression of donor and recipient genes. Genetic recombination is a naturally occurring biological process in virtually all organisms. Recently, the term recombinant DNA has taken on a specific meaning because of major advances that have occurred in our understanding of plasmids and DNA metabolism. We are now able to routinely isolate genes from various organisms and incorporate them into eukaryotic or prokaryotic cells. The result has been the development of technology that makes it possible to manufacture enormous quantities of biologically active and 


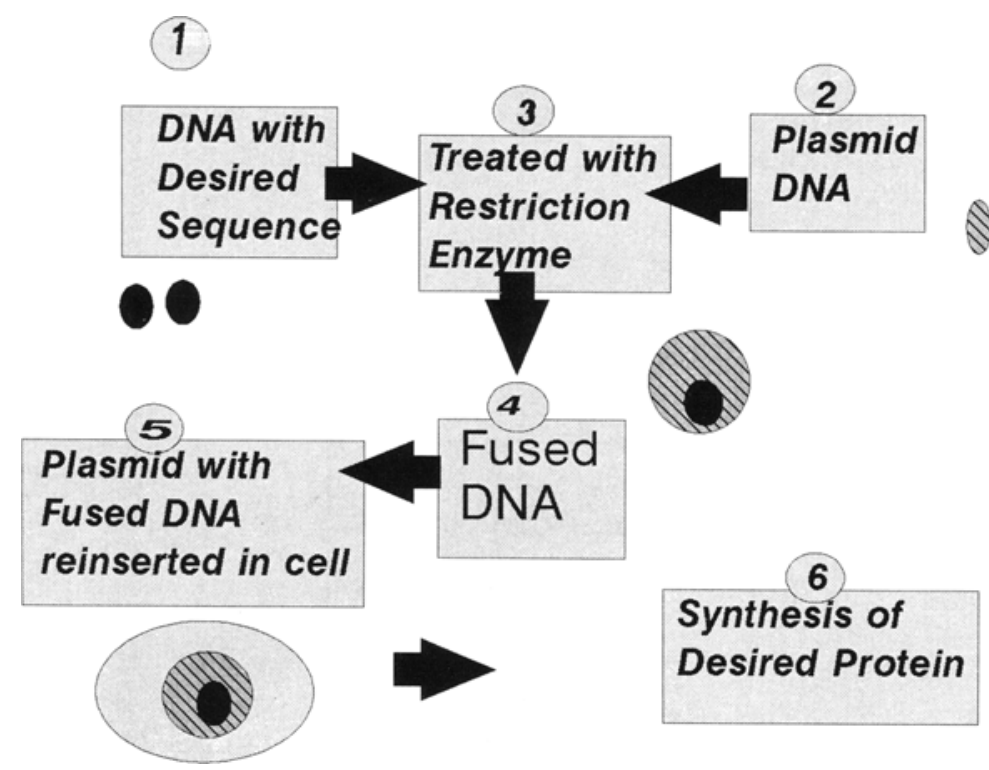

Fig. 3. Recombinant DNA preparations.

clinically important substances, to insert genes into metabolically deficient cells, or to insert resistance genes into normal human cells to protect them during chemotherapeutic treatment of neoplasia.

In the laboratory, recombinant DNA results from joining segments of DNA from different sources in vitro. Usually, the DNA segments are derived from different species. After introducing recombinant DNA into bacterial cells, the organism synthesizes the gene products of the newly acquired DNA. Special enzymes, called restriction enzymes, are required to produce recombinant DNA. This family of enzymes recognizes unique sites on the DNA molecules that are short, symmetrical sequences of bases. Restriction enzymes cut double-stranded DNA (both plasmid and foreign DNA) within these unique sites at staggered positions on both strands. This results in several pieces of DNA with single-stranded self-complementary ends. The cut foreign DNA pieces are mixed with the cut plasmid DNA pieces and, with the help of a DNA ligase, join together to form a recombination of foreign and plasmid DNA.

Once constructed, the recombinant plasmid is introduced into a bacterial cell by a process called transformation. Chemical substances are used to treat the cell walls of the recipient bacteria to remove structural barriers and increase their permeability to DNA. Transformed cells become hybrids, which carry a plasmid containing recombinant DNA in addition to their own genomic DNA. Each time the bacterium divides, so does the plasmid, thus maintaining 
the recombinant DNA. Plasmid recombinant DNA is transcribed and translated in products harvested from cell cultures and utilized in a variety of applications. Most bacterial cells do not readily secrete substances they synthesize into the culture medium. Therefore, cells must be collected and lysed to harvest the gene product of interest. Current efforts in genetic engineering aim at generating recombinant cells that naturally secrete their product into culture medium.

Another focus in genetic engineering is using eukaryotic cells as recipients of recombinant DNA and as producers of recombinant DNA products. Different technology is required to construct plasmids containing eukaryotic genes intended to synthesize and secrete a particular product. The problem is that eukaryotic genes consist of two regions, exon regions, which code for the protein product, and intron regions or intervening sequences within the gene, which do not code for a protein product. Eukaryotic cells transcribe the entire sequence of the gene (both exons and introns), and then excise the intron regions of the messenger RNA (mRNA) and splice the exon regions of the mRNA to form the sequence that will be translated into functional protein.

Bacterial cells do not contain enzymes that can excise intron RNA. Therefore, a bacterial cell cannot make functional mRNA or protein from eukaryotic genes. For eukaryotic genes to be functional in bacterial cells, a DNA copy of the eukaryotic mRNA is made in vitro with viral reverse transcriptase. This complementary DNA (cDNA) represents the entire coding sequence of DNA for the protein of interest (containing all of the exons, but no introns). The cDNA is then introduced into a bacterial cell in the form of a recombinant plasmid and can be transcribed and translated.

Recombinant DNA research has increased our understanding of gene regulation and has provided a means for producing enormous quantities of clinically important biological substances. The contributions of recombinant DNA to modern medicinal therapeutics include (1) production of natural and synthetic peptides, (2) subunit vaccines, (3) MAbs, (4) nucleic acid hybridization probes for in vitro and in vivo diagnostics and biological imaging, (5) production of therapeutic targets for rational drug design, and (6) the use of cloned enzymes as stereospecific catalysts in large-scale production of small medicinal molecules. For instance, human genes have been inserted into bacterial DNA for the production of somatostatin, human growth hormone, insulin, and interferon. Growth factors, such as epidermal growth factor (EGF); lymphokines, such as tumor necrosis factor (TNF), and interleukins (IL-1 through IL-7) are also being produced in this manner. 
Recombinant vaccines, such as the recombinant form of hepatitis B vaccine, have been successfully used for immunization. Similarly, peptide factors, such as streptokinase, which is used clinically for the dissolution of blood clots, are now being manufactured by genetically engineered bacteria. Clearly, recombinant DNA technology provides the potential for producing virtually any biological molecule used for clinical therapeutic purposes. Use of similar technology for other situations, such as the insertion of genes to offset metabolic deficiencies or provide resistance to chemotherapeutic agents, requires more sophisticated engineering. These genes must be regulated so as to become an integral part of the cell's life.

\section{The Clinical Immunology Laboratory and AIDS}

The acquired immunodeficiency syndrome (AIDS) will be used to illustrate how the aforementioned methods have been applied in the laboratory. However, the vastness of AIDS research makes it necessary to focus on a relatively small segment of this subject. We will discuss the application of flow cytometry, ELISA, MAbs, and recombinant DNA to the study of the HIV-1 envelope protein, gp120. This well-described glycoprotein is of great interest, because it functions to attach viral particles to the CD4 surface antigen of cells. Antibodies to gp120 may also neutralize this virus, thus making this of considerable importance in vaccine research. The rest of this paper will give an overview of how the methods described earlier were used in identifying the CD4 molecule as the ligand of gp120, in mapping the epitopes of gp120, and in generating and evaluating recombinant gp120 vaccines.

\section{gp120 and CD4}

Mammalian T-lymphocytes can be segregated into two major groups based on surface protein markers. Those that possess the CD4 antigen are considered to be of the "helper" type while those that express CD8 are termed "suppressor/cytotoxic" T-cells. Although relatively early observations had shown that infection by HIV was associated with $\mathrm{CD}^{+} \mathrm{T}$-cells, understanding the relationship of CD4 and gp120 required the use of MAbs. Dalgeish et al. (70) and Klatzmann et al. (71) were able to block the in vitro infection (as measured by reverse transcriptase activity and syncytia formation) of $\mathrm{CD}^{+}$cells with HIV by preincubating target cells with MAbs to CD4. MAbs to other target antigens did not have the same protective effect. The direct binding of HIV to $\mathrm{CD}^{+}$cells was demonstrated by McDougal et al. (72). Following incubation of lym- 
phocytes with HIV, they were able to detect the cell-bound viral particles through the use of fluoresceinated antibodies to HIV and flow cytometry. The CD4 phenotype of these susceptible cells were confirmed by flow cytometry. They then showed that preincubation of $\mathrm{CD}^{+}$cells with virus blocked the detection of the CD4 antigen with MAbs. Also, through recombinant DNA technology, the transfer of the CD4 gene and its expression to previously CD4- human cells made these cells susceptible to infection by HIV (73). In regard to gp120 and CD4, the binding of CD4 with gp120 was demonstrated by the ability of CD4 to coprecipitate the radiolabeled viral gp120 (74). Also, the introduction of changes into the nucleotide sequence of the gp120 gene was shown to affect gp120-CD4 association (75).

\section{Epitope Mapping}

Studying the immune response to the AIDS virus has at least two major applications. One is determining if a response is generated to the etiologic agent and, if so, why individuals still succumb to this disease. The other is the development of vaccines to prevent infection by HIV. The function of gp120 in initiating contact between the virus and its target cell, coupled with the known antibody responses to this protein, make gp120 of central importance in AIDS research.

Despite the attractiveness of gp120 as a target of vaccine development, a major obstacle is the variability within the gp120 amino acid sequence. Conserved and hypervariable regions have been documented in the amino acid sequences of different strains of gp120 $(76,77)$. Of concern was the finding that the predicted antigenic regions were also the most variable, suggesting that vaccines would be unlikely to enable individuals to respond favorably to the many HIV strains to which they could be exposed. However, the finding that uninfected children born to seropositive mothers were protected by maternal anti-gp 120 antibodies implied that protection can be achieved (78). In fact, much has been written about the neutralizing activity of antisera to recombinant, synthetic, and purified gp120. Most of the neutralizing activity (generally measured as the inhibition of syncytia formation or reverse transcriptase activity) is centered on epitopes on the third hypervariable region (V3), also called the principal neutralizing determinant (PND). As expected, the antibodies tended to be type- or variant-specific in that they did not neutralize heterologous HIV isolates (79-81). On the other hand, there were also reports of antisera neutralizing several HIV isolates, suggesting that responses to conserved epitopes may be generated (82-84). 
Table 3

Binding Specificities of Monoclonal Antibodies to gp120

\begin{tabular}{|c|c|c|c|c|}
\hline MAb & MAb type & Epitope $^{a}$ & $\begin{array}{c}\text { Neutralizes } \\
\text { HIV }^{b}\end{array}$ & Refs. \\
\hline $110-1$ & Mouse & $\mathrm{C}, \mathrm{CD}^{-}$, aа 489-511 & No & 85 \\
\hline $110-4$ & Mouse & $\mathrm{V}, \mathrm{V3}^{+}, \mathrm{CD}^{-}$, aa $303-323$ & Yes & 85 \\
\hline 9284 & Mouse & $\mathrm{V}, \mathrm{V3}^{+}$, aa $307-330$ & Yes & 86 \\
\hline $0.5 \beta$ & Mouse & $\begin{array}{l}\text { Closer to } \mathrm{COOH} \text { terminus } \\
\text { than } 9284\end{array}$ & Yes & 86 \\
\hline 5C2E5 & Mouse & $\mathrm{L}, \mathrm{C}, \mathrm{CD}^{+}$, aa $397-439$ & Yes & 87 \\
\hline $\mathrm{N} 70-1.9 \mathrm{~b}$ & Human & $\mathrm{D}, \mathrm{V}, \mathrm{V3}^{+}$ & Yes & 88 \\
\hline P4/D10 & Mouse & $\mathrm{C}, \mathrm{V}^{+}$, aa $304-323^{c}$ & Yes & 89 \\
\hline L5.1 & Mouse & C, aa $79-103$ & No & 89 \\
\hline RL16.76.1 & Mouse & $\mathrm{C}$, aa $251-270$ & No & 90 \\
\hline $1 \mathrm{E3}$ & Mouse & V, Carbohydrate Tn & Yes & 91 \\
\hline G3-4 & Mouse & $\mathrm{D}, \mathrm{V3}^{-}, \mathrm{CD4}^{+}$ & Yes & 92 \\
\hline 448-D & Human & $\mathrm{D}, \mathrm{C}, \mathrm{V3}^{-}, \mathrm{CD}^{+}$ & Yes & 93 \\
\hline 559/64-D & Human & $\mathrm{D}, \mathrm{C}, \mathrm{V3}^{-}, \mathrm{CD}^{+}$ & Yes & 93 \\
\hline 588-D & Human & $\mathrm{D}, \mathrm{C}, \mathrm{V3}^{-}, \mathrm{CD}^{+}$ & Yes & 93 \\
\hline 450-D & Human & $\mathrm{L}, \mathrm{C}, \mathrm{V3}^{-}, \mathrm{CD}^{+}$, aa $487-509$ & No & 93 \\
\hline BAT085 & Mouse & $\mathrm{L}, \mathrm{V}, \mathrm{V} 2^{+}, \mathrm{CD}^{-}$, aa $169-183$ & Yes & 94 \\
\hline G3-136 & Mouse & $\mathrm{D}, \mathrm{V}, \mathrm{V}^{+}, \mathrm{CD}^{+}$, aa $169-183$ & Yes & 94 \\
\hline
\end{tabular}

${ }^{\circ} \mathrm{D}$, discontinuous or $\mathrm{L}$, linear; $\mathrm{C}$, conserved or $\mathrm{V}$, variable, determined by crossreactivity of $\mathrm{MAb}$ with different strains of $\mathrm{HIV}$ or by comparison with amino acid map by Modrow et al.; $\mathrm{V3}^{+}$, located in V3; V3-, not located in V3; $\mathrm{CD4}^{+}$, inhibits gp120/CD4 binding; CD4-, does not inhibit gp120/CD4 binding; aa, amino acid residues.

${ }^{b}$ Neutralization parameters include blocking of gp120/CD4 binding, syncytia formation, and cytopathic effect.

cAlthough this segment of gp120 is considered variable, Åkerblom et al. identified a conserved site within V3, which may have allowed for the broad specificity of this neutralizing antibody.

In order to study the immune response to gp120 in more detail, epitope mapping with MAbs was done. By generating MAbs to segments of the macromolecule, whether these segments are conformational or linear, the immunogenicity of these individual segments and their importance in viral neutralization can be analyzed. Table 3 gives a representative sample of publications that reported on the ability of anti-gp120 MAbs to neutralize viral activity and their locations of binding on gp120. As noted, the functional characteristics of these MAbs varied according to whether their epitopes were:

1. Linear or discontinuous;

2. Considered to be segments of hypervariable or conserved amino acid residues;

3. Part of the CD4 binding site; and

4. Important in viral neutralization. 
One consistency appears to be that all MAbs that did not neutralize virus had conserved epitopes. Also, all MAbs that bound to the V3 region had neutralizing activity.

One MAb, P4/D10, was representative of six MAbs that recognized the principal neutralizing determinant, yet neutralized a wide variety of HIV isolates. Åkerblom et al. (89) identified a conserved four-amino-acid segment within the V3 region that may have been responsible for this activity. This was done with MAbs to gp120 derived from the immunization of mice with purified gp120, recombinant and synthetic linear gp120 peptides, and the ELISA. The reactivity of these MAbs to HIV were first measured by their ability to neutralize viral infectivity and their ability to bind to recombinant gp120 (rgp120) by the indirect ELISA. These MAbs were then grouped according to their gp120 epitope specificities. This was done by a competitive ELISA in which one MAb was used to block the binding of another to rgp120. Three general epitope specificities were identified. In order to further define the specific epitopes recognized by these MAbs, indirect ELISA was performed using 15-amino-acid synthetic peptides representative of gp120 epitopes. P4/D10 was one of six MAbs that reacted strongly with sequences $304-318$ and weakly with 309-323. Another group, represented by L5.1, bound to determinants closer to the amino terminus of gp120. These specificities were also confirmed by a competitive ELISA in which individual MAbs were incubated concurrently with two different synthetic peptides, one solubilized in the buffer and the other bound to the solid phase (plastic well). The binding of MAbs specific for the solid-phase antigen should be inhibited by the same antigen in solution, but not by different antigens. Fine mapping of the epitope of P4/D10 was done using a series of eight-amino-acid peptide sequences that were constructed with seven-amino-acid overlaps; this was done for gp120 sequences from nine HIV strains. Interestingly, all six neutralizing antibodies of the P4/D10 group responded to the sequence QRGPRG. The conserved GPRG was predicted to form a $\beta$ turn, and neighboring residues were thought to be important in the presentation of this sequence. Thus, relatively constant regions may be found among variable regions to which vaccine development can be directed.

The ELISA may also be used to measure other characteristics of anti-gp120 MAbs. Karwowska et al. (93) were able to determine the binding affinities of their MAbs to recombinant gp120. Basically, known concentrations of a MAb were preincubated with varying quantities of rgp120. These mixtures were then added to ELISA plates with wells coated with the rgp120; the coated wells then reacted with the unbound antigens. Dissociation constants were then determined from these data. 
In order to determine if the epitopes of anti-gp120 MAbs were also CD4 binding sites, flow cytometry has been used. The incubation of gp120 with CD4+ target cells, followed by antibodies 9284 (86), 110-1, and 110-4 (85); fluoresceinated antiimmunoglobulins; and flow cytometry analyses confirmed that gp120 bound to their targets. Inhibition studies in which gp120 was preincubated with MAbs showed that 9284 and 110-1 did not interfere with binding to CD4. At very high concentrations, $110-4$ did provide some inhibition. However, this was thought to be artifactual, because the concentrations of 110-4 required for viral neutralization was much lower. Therefore, the epitopes recognized by these MAbs were probably not within the CD4 binding regions.

\section{Recombinant Vaccines}

AIDS is a chronic condition that ultimately leads to death through opportunistic infections. Although treatments for the HIV and subsequent infections are being studied, prevention assumes the use of vaccines. In this regard, the response to gp 120 has been of interest to researchers, and immunization with gp120 obtained from recombinant DNA technology is one the major strategies currently being used. Various aspects of the human immune response to rgp120 has been reported, including the induction of antigen-specific cytotoxic T-lymphocytes (95) and salivary antibodies (96). Vaccination studies in humans and baboons will serve as examples of how the methods described in this paper have been used in immunization protocols and assessments of efficacy.

Gorse et al. (97) reasoned that gp120, which retains its native conformational epitopes, are more likely to generate useful humoral responses to viral infection than denatured antigens. Their vaccine was derived from an infectious clone of HIV $-1_{\text {LAV }}$. The gp160 was produced by cultured insect cells transfected with a recombinant baculovirus expression vector containing the gp160 gene (gp120 is a cleavage product of gp160, the other gene product being gp41). Human volunteers were innoculated with this subunit vaccine supplemented with an alum adjuvant. Using flow cytometry, the researchers were able to detect native-antigen-specific antibodies to HIV gp160, including those of two other strains. The detection method used HIV-infected or rgp160-pulsed cell lines that expressed the gp160 antigens on their surfaces. Serum antibodies bound to these cells could then be detected by fluoresceinated antihuman antibodies and flow cytometry. These results were confirmed by ELISA; the antigens used included both whole viral lysates and 
rgp160. Although viral neutralization assays were not done, this was a positive step toward vaccine development.

Other researchers also believed that native antigens were more likely than denatured antigens to generate protective immunity. This is especially important, because antibodies to carbohydrate epitopes have been described (91). Toward this end, Haigwood et al. (98) produced native, glycosylated $\mathrm{rgp}^{120_{\mathrm{SF} 2}}$ in Chinese hamster ovary cell cultures. Immunizations of baboons with this antigen were compared to denatured rgp 120 produced by yeast cells. Haigwood et al. also evaluated the effects of the timing of immunizations and different adjuvants on the immune responses. Using two viral neutralization assays (syncytia formation and gag protein production), they noticed that the native antigen gave humoral responses of higher titers directed to a broader range of HIV isolates than the denatured antigen. Comparisons of antigen-specific antibody titers were also confirmed by ELISA using the recombinant antigens. The results of this study demonstrated that immune responses to conserved epitopes, common to a relatively large number of HIV isolates, are much more likely to be generated by native recombinant antigens than denatured, linear antigens. They also noted that not all of the HIV isolates neutralized by native gp120 antisera contained the conserved GPRG sequence, again suggesting that useful conserved epitopes are conformational and not linear. Finally, adjuvants were essential in the development of responses to heterologous strains of virus.

Leukocyte proliferation assays using rgp160 as antigens have also be used as measurements of the effectiveness of rgp160 as an immunogen. Peripheral blood leukocytes from gp160-immunized healthy human volunteers were exposed to rgp160 in vitro to generate secondary immune responses $(99,100)$. The results showed that immunization of healthy people does generate an antigen-specific cellular immune response without compromising the ability of leukocytes to respond to other stimuli, such as mitogens.

\section{Conclusion}

The four technologies outlined in this paper are widely used in the clinical diagnosis of, and research into, many immunological diseases. They are also of immense importance in biotechnology. It is hoped that this overview of concepts and applications of flow cytometry, ELISAs, and recombinant DNA gives the reader an appreciation of the numerous ways in which these technologies can be used in the immunology laboratory. 


\section{References}

1. Bator, J. M., Groves, M. R., Price, B. J., et al. (1984), Cytometry 5, 34.

2. Sharpless, T. K. and Melamed, M. R. (1976), J. Histochem. Cytochem. $24,257$.

3. Horan, P. K. and Wheeless, L. L., Jr. (1977), Science 198, 149.

4. Cambier, J. L., Kay, D. B., and Wheeless, L. L. (1979), J. Histochem. Cytochem. 27, 321.

5. Watt, S. M., Burgess, A. W., Metcalf, D., et al. (1980), J. Histochem. Cytochem. 28, 934.

6. Hoffman, R. A., Kung, P. C., Hansen, W. P., et al. (1980), Proc. Natl. Acad. Sci. USA 77, 4914.

7. Hoffman, R. A. and Hansen, W. P. (1981), Int. J. Immunopharmacol. $3,249$.

8. Thorell, B. (1983), Cytometry 4, 61.

9. Benson, H. C., Meyer, R. A., Zaruba, M. E., et al. (1979), J. Histochem. Cytochem. 27, 44.

10. Aubin, J. (1979), J . Histochem. Cytochem. $27,36$.

11. Jongkind, J. F., Verkerk, A., Visser, W. J., et al. (1982), Exp. Cell. Res. $138,409$.

12. Look, A. T., Melvin, S. L., Williams, D. L., Brodeur, G. M., Dahl, G. V., Kalwinsky, D. K., Murphy, S. B., and Mauer, A. M. (1982), Blood 60, 959.

13. Taylor, I. W. (1980), J. Histochem. Cytochem. 28, 1021.

14. Vindelov, L. L., Christensen, I. J., and Nissen, N. I. (1982), Cytometry $3,328$.

15. Langlois, R. G., Yu, L.-C., Gray, J. W., et al. (1982), Proc. Natl. Acad. Sci. USA 79, 7876.

16. Jensen, R. H., Langlois, R. G., and Mayall, B. H. (1977), J. Histochem. Cytochem. 25, 954.

17. Darzynkiewicz, Z., Traganos, F., and Melamed, M. R. (1980), Cytometry $1,98$.

18. Cowden, R. R. and Curtis, S. K. (1981), Histochemistry 72, 11.

19. Pollack, A., Prudhomme, D. L., Greenstein, D. B., Irvin, G. L., III, Claflin, A. J., and Block, N. L. (1982), Cytometry 3, 28.

20. Wallen, C. A., Higashikubo, R., and Dethlefsen, L. A. (1982), Cytometry $3,155$.

21. Stohr, M., Vogt-Schaden, M., Knoblock, M., Vogel, R., and Futterman, G. (1987), Stain Technol. 53, 205.

22. Crissman, H. A. and Steinkamp, J. A. (1982), Cytometry 3, 84.

23. Stohr, M. and Vogt-Schaden, M. (1980), Acta Pathol. Microbiol. Scand., Sec. A, Suppl. 274, 96.

24. Darzynkiewicz, Z., Traganos, F., Staiano-Coico, L., Kapuscinski, J., and Melamed, M. R. (1982), Cancer Res. 42, 799.

25. Jacobs, D. B. and Pipho, C. (1983), J. Immunol. Meth. 62, 101.

26. Beumer, T., Pennings, A., Beck, H., et al. (1983), Cytometry 4, 244.

27. Muirhead, K. A., Steinfeld, R. C., Severski, M. C., et al. (1984), Cytometry $5,268$.

28. Watson, J. V. (1980), Cytometry 1, 143.

29. Malin-Berdel, J. and Valet, G. (1980), Cytometry 1, 222. 
30. Dunn, P. A. and Tyrer, H. W. (1981), J. Lab. Clin. Med. 98, 374.

31. Bassoe, C.-F., Laerum, O. D., Glette, J., Hopen, G., Haneberg, B., and Solberg, C. O. (1983), Cytometry 4, 254.

32. Valet, G., Raffael, A., Moroder, L., Wunsch, E., and Ruhenstroth-Bauer, G. (1981), Naturwissenschaften 68, 265.

33. Gerson, D. F. (1982), in Intracellular pH: Its Measurement, Regulation, and Utilization in Cellular Functions, Nuccitelli, R. and Deamer, R. L., eds., Liss, New York, p. 125.

34. Kute, T. E., Linville, C., and Barrows, G. (1983), Cytometry 4, 132.

35. Van, N. T., Raber, M., Barrows, G. H., et al. (1984), Science 224, 876.

36. Noguchi, P. D., Johnson, J. B., and Browne, W. (1981), Cytometry 1, 390.

37. Dolbeare, F., Gratzner, H. G., Pallavicini, M. G., et al. Proc. Natl. Acad. Sci. USA 80, 5573.

38. Lindmo, T. and Steen, H. B. (1977), Biophys. J. 18, 173.

39. Epstein, M., Norman, A., Pinkel, D., et al. (1977), J. Histochem. Cytochem. 25, 821.

40. Godin, J. W. and Burns, J. F. (1981), J. Immunol. 127, 256.

41. Fingerroth, J. D., Weis, J. J., Tedder, T. F., Strominger, J. L., Biro, P. A., and Fearon, D. T. (1984), Proc. Natl. Acad. Sci. USA 81, 4510.

42. Hallberg, T., Dohlsten, M., and Baldetorp, B. (1984), Scand. J. Hematol. 32, 113.

43. Sklar, L. and Finney, D. A. (1982), Cytometry 3, 161.

44. Lanier, L. L. and Loken, M. R. (1984), J. Immunol. 132, 151.

45. Parks, D. R., Hardy, R. R., and Herzenberg, L. A. (1984), Cytometry 5, 159.

46. Seligmann, B., Chused, T. M., and Gallin, J. I. (1981), J. Clin. Invest. 68, 1125.

47. Felber, S. M. and Brand, M. D. (1983), Biochem. J. 210, 885.

48. Tsien, R. Y., Pozzan, T., and Rink, T. J. (1982), J. Cell. Biol. 94, 325.

49. Weiss, A., Imboden, J., Shoback, D., et al. (1984), Proc. Natl. Acad. Sci. USA 81, 4169.

50. Ohsako, S. and Deguchi, T. (1984), Biochem. Biophys. Res. Commun. $122,333$.

51. Laerum, O. D. and Farsund, T. (1981), Cytometry 2, 1.

52. Shapiro, H. M. (1983), Cytometry 3, 312.

53. Kohler, G. and Milstein, C. (1975), Nature 256, 495.

54. Kozbor, D. and Roder, J. C. (1983), Immunol. Today 4, 72.

55. Nowinski, R., Berglund, C., Lane, T., et al. (1980), Science 210, 537.

56. Schlom, T., Wunderlich, D., and Teramoto, Y. A. (1980), Proc. Natl. Acad. Sci. USA 77, 6841.

57. Kozbor, D., Roder, J. C., Chang, T. H., Steplewski, Z., and Koprowski, H. (1982), Hybridoma 1, 323.

58. Croce, C. M., Linnenbach, A., Hall, W., Steplewski, Z., and Koprowski, H. (1980), Nature 288, 488.

59. Shoenfeld, Y., Hsu-lin, S. C., Gabriels, J. E., Silberstein, L. E., Furie, B. C., Furie, B., Stollar, B. D., and Schwartz, R. S. (1982), J. Clin. Invest. 70, 205.

60. Steinitz, M., Klein, G., Koskimies, S., et al. (1977), Nature 269, 420.

61. Kozbor, D. and Roder, J. C. (1981), J. Immunol. 127, 1275.

62. Steinitz, M. and Tamir, S. (1982), Eur. J. Immunol. 2, 126.

63. Farrands, P. A., Rerkins, A. C., Rimm, M. V., Embleton, M. J., Hardy, J. D., Baldwin, R. W., and Hardcastle, J. D. (1982), Lancet 1, 397. 
64. Thorpe, P. E., Edwards, D. C., Davies, A. J. S., et al. (1982), in Monoclonal Antibodies in Clinical Medicine, McMichael, A. J. and Fabre, J. W., eds., Academic, New York, p. 167.

65. Gallego, J., Price, M. R., and Baldwin, R. W. (1984), Int. J. Cancer 33, 737.

66. Vallera, D. A., Ash, R. C., Zaniani, E. D., Kersey, J. H., LeBien, T. W., Beverley, P. C., Neville, D. M., Jr., and Youle, R. J. (1983), Science 222, 512.

67. Reynolds, C. P., Black, A. T., Saur, J. W., et al. (1985), Transplant. Proc. $17,434$.

68. Huse, W. H., Sastry, L., Iverson, S. A., Kang, A. S., Alting-Mees, M., Burton, D. R., Benkovic, S. J., and Lerner, R. A. (1989), Science 246, 1275.

69. Ekins, R. P. (1985), in Alternative Immunoassays, Collins, W. P., ed., Wiley, Chicester, p. 219.

70. Dalgeish, A. G., Beverley, P. C. L., Clapham, P. R., Crawford, D. H., Greaves, M. F., and Weiss, R. A. (1984), Nature 312, 763.

71. Klatzmann, D., Champagne, E., Chamaret, S., Gruest, J., Guetard, D., Hercend, T., Gluckman, J. C., and Montagnier, L. (1984), Nature 312, 767.

72. McDougal, J. S., Mawle, A., Cort, S. P., Nicholson, J. K., Cross, G. D., Scheppler-Campbell, J. A., Hicks, D., and Sligh, J. (1985), J. Immunol. 135, 3151 .

73. Maddon, P. J., Dalgleish, A. G., McDougal, J. S., Clapham, P. R., Weiss, R. A., and Axel, R. (1986). Cell 47, 333.

74. McDougal, J. S., Kennedy, M. S., Sligh, J. M., Cort, S. P., Mawle, A., and Nicholson, J. K. (1986), Science 231, 382.

75. Kowalski, M., Potz, J., Basiripour, L., Dorfman, T., Goh, W. C., Terwillinger, E., Dayton, A., Rosen, C., Haseltine, W., and Sodroski, J. (1987), Science 237, 1351.

76. Willey, R. L., Rutledge, R. A., Dias, S., Tolks, T., Theodore, T., Buckler, C. E., and Martin, M. A. (1986), Proc. Natl. Acad. Sci. USA 83, 5038.

77. Modrow, S., Hahn, B. H., Shaw, G. M., Gallo, R. C., Wong-Staal, F., and Wolf, H. (1987), J. Virol. 61, 570.

78. Rossi, P., Moschese, V., Broliden, P. A., Fundaro, C., Quinti, I., Plebani, A., Giaquinto, C., Tovo, P. A., Ljunggren, K., and Rosen, J. (1989), Proc. Natl. Acad. Sci. USA 86, 8055.

79. Matthews, T. J., Langlois, A. J., Robey, W. G., Chang, N. T., Gallo, R. C., Fischeringer, P. J., and Bolognesi, D. P. (1986), Proc. Natl. Acad. Sci. USA 83, 9709.

80. Goudsmit, J., Debouck, C., Meloen, R. H., Smit, L., Bakker, M., Asher, D. M., Wolff, A. V., Gibbs, C. J., and Gajdusek, D. C. (1988), Proc. Natl. Acad. Sci. USA 85, 4478.

81. Javaherian, K., Langlois, A. J., McDanal, C., Ross, K. L., Eckler, L. I., Jellis, C. L., Profy, A. T., Rusche, J. R., Bolognesi, D. P., and Putney, S. D. (1989), Proc. Natl. Acad. Sci. USA 86, 6768.

82. Ho, D. D., Sarngadharan, M. G., Hirsch, M. S., et al. (1987), J. Virol. 61, 2024.

83. Ho, D. D., Kaplan, J. C., Rackauskas, I. E., Schooley, R. T., Rota, T. R., Kennedy, R. C., Chanh, T. C., and Sato, V. L. (1988), Science 239, 1021.

84. LaRosa, G. J., Davide, J. P., Weinhold, K., Waterbury, J. A., Profy, A. T., Lewis, J. A., Langlois, A. J., Dreesman, G. R., Boswell, R. N., and Shadduck, P. (1991), Science 2390, 932. 
85. Linsley, P. S., Ledbetter, J. A., Kinney-Thomas, E., et al. (1988), J. Virol. 62, 3695.

86. Skinner, M. A., Ting, R., Langlois, A. J., Weinhold, J. K., Lyerly, H. K., Javaherian, K., and Matthews, T. H. J. (1988), AIDS Res. Hum. Retroviruses 4, 187.

87. Lasky, L. A., Nakamura, G., Smith, D. H., Fennie, C., Shimasaki, C., Patzer, E., Berman, P., Gregory, T., and Capon, D. J. (1987), Cell 50, 975.

88. Robinson, J. E., Holton, D., Pacheco-Morell, S., et al. (1990), AIDS Res. Hum. Retroviruses 6, 567.

89. Åkerblom, L., Hinkula, J., Broliden, P.-A., Makitalo, B., Fridberger, T., Rosen, J., Villacres-Eriksson, M., Morein, B., and Wahren, B. (1990), AIDS 4, 953.

90. Robert, V., Resnicoff, M., Chermann, J.-C., et al. (1991), Mol. Cell. Biochem. 102, 115.

91. Hansen, J.-E. S., Nielsen, C., Arendrup, M., Olofsson, S., Mathiesen, L., Nielsen, J. O., and Clausen, H. (1991), J. Virol. 65, 6461.

92. Ho, D. D., Fung, M. S. C., Cao, Y., Li, X. L., Sun, C., Chang, T. W., and Sun, N. C. (1991), Proc. Natl. Acad. Sci. USA 88, 8949.

93. Karwowska, S., Gorny, M. K., Bushbinder, A., Gianakakos, V., Williams, C., Furest, T., and Zolla-Pazner, S. (1992), AIDS Res. Hum. Retroviruses 8, 1099.

94. Fung, M. S. C., Sun C. R. Y., Gordon, W. L., Liou, R. S., Chang, J. T. W., Sun, W. N., Daar, E. S., and Ho, D. D. (1992), J. Virol. 66, 848.

95. Orentas, R. J., Hildreth, J. E. K., Obah, E., et al. (1990), Science 248, 1234

96. Archibald, D. W., Herbert, C. A., Sun, D., Polydefkis, M., Smith, G. E., Clements, M. L., and Siliciano, R. F. (1990), J. AIDS 3, 954.

97. Gorse, G. J., Frey, S. E., Newman, F. K., et al. (1992), J. Clin. Microbiol. 30, 2606.

98. Haigwood, N. L., Nara, P. L., Brooks, E., Van Nest, G. A., Ott, G., Higgins, K. W., Dunlop, N., Scandella, C. J., Eichberg, J. W., and Steimer, K. S. (1992), J. Virol. 66, 172.

99. Tacket, C. O., Baqar, S., Munoz, C., et al. (1990), AIDS Res. Hum. Retroviruses 6, 535.

100. Gorse, G. J., Belshe, R. B., Newman, F. K., et al. (1992), Vaccine 10, 383. 